\title{
A cosmologia realista de Popper e sua contribuição para a discussão racional em Física
}

\author{
Popper's realistic cosmology and its contribution to racional discussion in \\ Physisc
}

\author{
WILLIAM CARLOS KUHN ${ }^{1}$
}

REMI SCHORN ${ }^{2}$

\begin{abstract}
Resumo: O presente artigo mostra que o realismo constitui a principal tese metafísica presente na filosofia de Popper e que esteve presente, de forma relevante, desde a Lógica da Pesquisa Científica até o Pós-escrito. Apesar de ter sido revista, passando de uma noção negativa para positiva, ampliou o universo de articulação teórico da sua filosofia e organizou sua proposta epistemológica. A defesa Popperiana do realismo está vinculada a uma concepção ética de fundo e uma concepção cosmológica que abrange uma ontologia da mudança e uma epistemologia falibilista. Sua concepção filosófica comporta desde um plano universal do pensamento metafísico, cosmológico, até um plano específico, das regras metodológicas, adequado ao estudo da ciência. O filósofo pensou que a tarefa da filosofia não se resume na análise de enunciados, mas se trata da elaboração de uma visão de totalidade da realidade capaz de constituir soluções a problemas teóricos reais do universo do conhecimento. Ele unificou sua concepção filosófica ao propor a teoria das Propensões e a mostrou como uma articulação das suas noções de objetivismo, realismo e de indeterminismo. Como forma de mostrar a relevância de sua cosmologia para o estudo da ciência, ele propôs dois experimentos em física e confrontou a sua concepção objetivista, realista e indeterminista com a rival teoria quântica, então subjetivista e antirrealista. $\mathrm{O}$ primeiro teste recebeu correções de Einstein através de uma carta, publicada em anexo à Lógica da Pesquisa Científica (L.Sc.D). O segundo teste, proposto em A Teoria dos Quanta e o Cisma na Física (Q.T.S.P), foi realizado em 1999 por Kim e Shih e, o resultado mostrou inconformidade com a previsão de Popper. Ambos, entretanto, contribuíram, ainda que de modo discreto, para a crítica racional no universo científico.
\end{abstract}

Palavras-chave: Realismo. Metafísica. Crítica.

Abstract: This article shows that realism is the main metaphysical thesis in Popper's philosophy and that has been present in a relevant way, since Logic of Scientific Discovery to Postscript. Although it was revised, changing from a negative to a positive notion, it expanded the universe of theoretical articulation of his philosophy and organized his epistemological proposal. The Popperian defense of realism is linked to an ethical background and a cosmological conception that convers an ontology of change and a fallibilist epistemology. His philosophical conception comports an universal plane of metaphysical, cosmological thought to the specific plane of methodological rules, appropriate to the study of science. The philosopher thought that the task of philosophy is not limited to the analysis of statements but it is the elaboration of a vision of totality of reality capable of providing solutions to real theoretical problems of the universe of knowledge. He unified his philosophical conception by proposing the theory of Propensity and showed it as an articulation of objectivism, realism, and his indeterminism notions. As

\footnotetext{
${ }^{1}$ Graduado em Filosofia pela UFSC (2012), Especialista na área de Ontologia e Epistemologia também pela UFSC. Mestre em Filosofia na área de Metafísica e Conhecimento pela UNIOESTE. Atualmente Leciona na rede privada de ensino. E-mail: willianckuhn@gmail.com.

${ }^{2}$ Doutor em Filosofia e Professor nos Cursos de Graduação e Pós-Graduação em Filosofia (Stricto Sensu) da UNIOESTE. E-mail: remirs@hotmail.com.
} 
a way of showing the relevance of his cosmology to the study of science, he proposed two experiments in physics and confronted his objectivist, realistic and indeterministic conceptions with the rival quantum theory, that it was subjectivist and antirealist. The first test received corrections from Einstein through a letter, attached to the Logic of Scientific Discovery (L.Sc.D). The second test, proposed in Quantum Theory and the Schism in Physics (Q.T.S.P) was carried out in 1999 by Kim and Shih, and the result showed nonconformity with Popper's prediction. Both, however, contributed, albeit discreetly, to rational criticism in the scientific universe.

Keywords: Realism. Metaphysics. Critics.

\section{O realismo e a decisão pela defesa de uma tese metafísica}

O tratamento de Popper relativamente ao realismo metafísico mudou desde a Lógica da Pesquisa Científica (que entender-se-á por L.Sc.D) até o pós-escrito. Na primeira fase de desenvolvimento de sua filosofia, o filósofo combateu o positivismo lógico ao criticar a pretensão de eliminação da metafísica pela via de análise da linguagem, mas, ao mesmo tempo, não sustentou explicitamente um realismo em sua Lógica da Pesquisa Científica, ainda que já se tivesse percebido o caráter metafísico dessa tese e a tivesse aceito implicitamente como uma fé. ${ }^{3}$

Mais tarde, ao rever suas concepções no pós-escrito, procurou mostrar que a obra antes desenvolvida, não era incompatível com essa tese metafísica ao afirmar que, mesmo não sendo um pressuposto nesta obra "constitui uma espécie de pano de fundo que dá corpo à nossa busca da verdade (POPPER, 1987, p. 106). Esse pano de fundo, em $O$ Realismo e o objetivo da ciência (doravante R.A.S) se vincula com o objetivo da ciência e leva Popper a se comprometer com a homogeneidade estrutural do mundo e com a noção de verdade correspondencial de tal forma que, parecem surgir, a partir daí, inconsistências em sua filosofia, especificamente com a noção de conhecimento como invenção humana. ${ }^{4}$ Além disso, essa aparente fragilidade em sua filosofia parece resultar de uma motivação psicológica e concomitantemente por ter procurado no pós-escrito vincular investigação científica como a busca da verdade, algo que não se fez notar em L.Sc.D. ${ }^{5}$

Nota-se, com isso, que o realismo popperiano é problemático em sua filosofia. Nesse sentido, surge a proposta de Caponi (1996), alicerçada em Putnam de uma alternativa internalista do conceito de verdade para o falseasionismo. ${ }^{6}$ Por outro lado, é possível aceitar que a noção de realismo metafísico de Popper, mesmo que tenha suscitado problemas, impulsionou Popper a ampliar a sua filosofia, levando-o

\footnotetext{
${ }^{3}$ Cf. POPPER, 2013, p. 36.

${ }^{4}$ Cf. CAPONI, 1992, p.17o.

${ }^{5}$ Cf. CAPONI, 1996, pp.20-21.

${ }^{6}$ CAPONI, 1996, pp.30-31.
} 
a uma compreensão mais global, uma cosmologia propensitiva ${ }^{7}$ capaz de enriquecer o debate e a compreensão sobre o mundo.

Popper foi um pensador que defendeu a crítica, ou a busca por objetividade como uma atividade produtiva para o conhecimento. As críticas que recebeu o levaram a reformular suas teses, ampliando sua compreensão. Após algumas dessas discussões Popper passa a defender o realismo e procura justificar os motivos de não tê-lo feito na obra que antecedeu ao Pós-escrito:

Paralelamente à correção de minha teoria do conhecimento, um dos meus objetivos no Postscript foi mostrar que o realismo da minha Logik der Forschung foi uma posição criticável ou discutível. Eu defendi que a Logik der Forschung foi uma obra de um realista, mas naquele momento eu não ousaria dizer muito sobre o realismo. $\mathrm{O}$ motivo foi que eu não tinha me dado conta que a posição metafísica, embora não testável, pode ser racionalmente criticável ou discutível. Eu tinha confessado ser um realista, mas eu havia pensado que isso não era mais do que uma confissão de fé. Desse modo, eu tinha escrito sobre um de meus argumentos realistas que "exprime a fé metafísica na existência de regularidades em nosso mundo" (a fé que eu compartilho, e sem ação prática é dificilmente concebível) (POPPER, 1974, p. 173).

O realismo mostra-se como a tese metafísica principal de Popper e uma evidência disso é o reconhecimento do filósofo de que sua obra magna, L.Sc.D baseia-se nessa conjectura, ainda que durante a época de escrita tenha se mantido como um pano de fundo, uma ideia reguladora para uma metodologia falseasionista em face de uma epistemologia falibilista.

É nítida a diferença de Popper no tratamento com o realismo em L.Sc.D e R.A.S. Essa mudança permitiu o filósofo a organizar sua epistemologia de modo a permitir uma discussão em torno da verdade e isso mostrou-se como um distanciamento evidente da metodologia meramente analítica do positivismo lógico, antes combatido por ele. A metafísica passou a ser aceita como significativa, ainda que o critério da objetividade de suas teses tenha se reservado ao modo de defesa crítica ou não, se balizada pela abertura à crítica racional. Assim sendo, a filosofia popperiana, após alguns desenvolvimentos, passou a admitir o realismo enquanto

\footnotetext{
7 O termo "propensão" pode ser entendido de modo amplo e sem perda de afinidade com a teoria propensitiva de Popper sendo entendido como um termo de aplicação na biológia, na psicologia, bem como em física e em economia (POPPER, 1989, p.210). De fato, a teoria das propensões de Popper tem uma grande amplitude na sua filosofia e estreita as fronteiras entre as disciplinas, ao se pretender uma cosmologia unificadora do pensamento. Assim, as propensões de Popper significam na teoria da probabilidade da física, por exemplo, "possibilidades" tanto quanto "distribuição de propriedades". As Propensões podem também ser entendidas de modo geral como "potencialidades para realizar algo". (Ibidem, p.199). São "relacionais" (Ibidem, p.210). Por fim, o que se pode entender de modo geral sobre essa teoria de Popper é que seu programa propensitivo, além de abarcar todos os sentidos acima citados, "é metafísico", "não-testável", "irrefutável" e "baseia-se na ideia metafísica de indeterminismo" (Ibidem, p.201).
} 
tese metafísica mediante a crença em regularidades e na existência de um mundo real, independente de um sujeito:

Em discussões com ele [Gomperz] foi que eu comecei a defender meu realismo, minha convicção de que há um mundo real, e que o problema do conhecimento é o problema de como descobrir este mundo. Eu me tornei convicto de que, se queremos discutir sobre isto, não devemos partir das nossas experiências dos sentidos (ou até mesmo nossos sentimentos, como a sua teoria demandava) sem cair nas armadilhas do psicologismo, idealismo, positivismo, fenomenalismo, até do solipsismo - todas as perspectivas que eu recusei considerar de modo sério. Meu senso de responsabilidade social me disse que tomar tais problemas seriamente era um tipo de traição intelectual - e um mau uso do tempo que nós deveríamos estar usando com problemas reais (POPPER, 1974, p.84).

Popper considera os problemas como fundamentais e os verdadeiros motivadores de discussão e investigação. Dentre os vários problemas de interesse para o filósofo está o problema da origem do conhecimento. Popper parece relacioná-lo aqui, com a ideia de descoberta, e esta, por sua vez, parece supor algo de externo ao sujeito, e isso corresponde ao realismo, ou pelo menos de uma das formulações de realismo.

\section{O realismo de senso comum, metafísico e científico e seus problemas}

Poucos foram os pensadores que levaram o ceticismo ao extremo, a ponto de duvidar da existência externa ao sujeito, como o caso de Pirro, que conta-se ter sido salvo por um de seus discípulos. Parece que a admissão da existência externa funciona como um pressuposto, mas sem nenhuma prova. Nesse sentido, Kant havia dito que "permanece um escândalo à filosofia e à razão humana que a existência de coisas fora de nós (...) devam ser aceitas somente pela fé". 8 Popper chama a aceitação da existência independente e exterior ao sujeito de formulação do senso comum. ${ }^{9}$ Essa concepção parece carregar consigo outro pressuposto: ao assumir que há algo externo, admite-se que, para perceber esse algo, e, consequentemente, para dizer algo a respeito dele, deve-se admitir alguma correspondência entre os enunciados acerca dele e os seus estados de coisas propriamente ditos, ou seja, admite-se a verdade como correspondência. Popper parece, às vezes recuar ao supor a versão mais simplificada do realismo:

(...) em ocasiões, Popper parece entender por "realismo" algo distinto da postulação da concepção clássica de verdade. Com efeito, há momentos em que Popper parece pensar que o realismo se esgota na já referida assumpção (empírica e conjecturalmente

\footnotetext{
${ }^{8}$ Apud FERNANDES, 1981, p.203.

9 POPPER, 1972, p. 44.
} 
baseada) de que existem coisas tais como corpos físicos, mentes ou instituições; (...) (CAPONI, 1992, pp. 170-171).

Mas o que merece atenção e que trouxe consequência mais sérias à sua filosofia é a versão expandida do realismo, que assume, além da mera existência externa a aceitação de leis da natureza, ou seja, uma regularidade ou homogeneidade na estrutura do mundo, isto é, a formulação do realismo metafísico. Ora, essa concepção parece, a princípio, estar em sintonia com o processo de investigação científica, então, por qual motivo não chama-lo de realismo científico?

Podemos asseverar que quase todas, senão todas, as teorias físicas, químicas ou biológicas implicam realismo, no sentido de que, se forem verdadeiras, também o realismo deve ser verdadeiro. Esta é uma das razões pelas quais certas pessoas falam de "realismo científico". E é uma razão muito boa. Em vista de sua (aparente falta de testabilidade, acontece que eu mesmo prefiro chamar ao realismo "metafísico" em vez de "científico") (POPPER, 1999, pp. 4748).

Popper é reconhecido por superar a concepção positivista de que a metafísica deva ser eliminada do rol da ciência porque seus enunciados não podem ser reduzidos a sentenças protocolares, isto é, sentenças básicas de observação. O que o filósofo falibilista fez nesse sentido foi admitir a metafísica como constituída de enunciados não testáveis, mas, nem por isso destituída de significado, por conta de ser possível criticá-las no plano racional. Assim, a testabilidade parece ser uma distinção entre aspectos científicos e metafísicos. Com efeito, caberia chamar o realismo de científico por conta de as teorias serem corroboradas?

Só é possível a corroboração onde é possível a falseamento, e, por isso, o êxito de algumas teorias científicas só poderia considerar-se como uma corroboração do realismo se o fracasso das mesmas tivesse podido ser considerado como um falseamento. Mas isso não é possível; e, portanto, não cabe falar de "realismo científico", mas de "realismo metafísico" (CAPONI, 1996, p.15).

Caponi (1996) traz motivos para se pensar que não é possível, visto que aceitar unicamente as teorias não refutadas como corroborações do realismo e ignorar as teorias falsificadas como sendo falsificação do realismo pareceria uma atitude controversa. Assim sendo, parece que somos inclinados a aceitar a princípio duas formulações de realismo em Popper: senso comum e metafísico. Entretanto, aquela que mais nos interessa é a segunda versão, é sobre ela que trabalharemos mais extensamente.

Popper foi um dos filósofos que aceitou o desafio de levar a defesa do realismo metafísico às suas últimas consequências, apesar de ter admitido o realismo (ainda antes de dar uma formulação clara) como uma profissão de fé na Lógica da Pesquisa 
Científica. ${ }^{10}$ Popper procurou tornar explícitos os motivos de não ter defendido explicitamente o realismo e indica que, apesar disso, já o aceitava intuitivamente. Um dos problemas mais importantes para o realismo popperiano não parece ser a mudança de atitude, mas que, ao assumir uma defesa, Popper se deu conta de apenas um problema: a aceitação da homogeneidade estrutural:

Newton foi levado, pela sua teoria da ação à distância, à crença de que o espaço era o sensorium de Deus. $\mathrm{O}$ argumento é, de certo modo, fantástico, sem dúvida; mas é mais sério do que parece à primeira vista. É que a dificuldade é muito concreta. As distâncias do universo são imensas. A ação à distância significaria que os efeitos gravitacionais eram, como a Divindade, omnipresentes no mundo inteiro. Newton, tal como Einstein, sentiu-se incapaz de aceitar a ação à distância como sendo uma propriedade da mecânica da natureza. Sentiu o mistério dela e atribui-a a Deus (POPPER, 1987, p.167).

A atitude de mostrar dificuldades na tese do realismo metafísico, que se propõe a defender, parece de uma honestidade intelectual louvável. De fato, Popper, enquanto defensor do falibilismo e do falseasionismo é, de certa forma, impelido a defender suas teses sem se evadir de possíveis contra evidências. Mas, além desse problema admitido, não percebeu que havia outro problema, talvez ainda maior para sua filosofia.

(...) Esta é uma tese que Popper acrescentou à sua teoria do método sem ter prestado a devida atenção ao fato de que a mesma entra em conflito com certa caracterização do conhecimento que está na base de tal teoria. Em particular, nos parece que a concepção de verdade como correspondência entre teoria e realidade em si em desacordo com a caracterização do conhecimento como invenção cultural e social; isto é: como produto humano (...) (CAPONI, 1992, p.170).

Depois da L.Sc.D, Popper, ao desenvolver sua teoria falseasionista do método, aceitou a tese da verdade como correspondência. Isso, por um lado possibilitou, conforme Caponi (1996), a discussão racional acerca da verdade. O motivo principal de ter entrado em tal discussão - inédita se comparada com a discussão da Lógica da Pesquisa Científica - parece ter sido o motivo de entender que tal concepção correspondencial, por ser desprovida de um critério (como a verificabilidade, por exemplo) era a única opção compatível com a falseabilidade e seu realismo metafísico. O problema, conforme conjectura Caponi (1992), é que Popper parece criar um problema de incoerência na aceitação concomitante das seguintes teses: a) a verdade se dá na correspondência entre teoria e realidade; b) o conhecimento é produto humano. Ora, se o conhecimento implica verdade, e esta se dá pela correspondência com algo externo ao sujeito, não parece evidente que esse

${ }^{10}$ Cf. POPPER, 2005, p. 173. 
conhecimento, que exige a noção de verdade, seja fruto de uma correspondência com uma realidade externa ao sujeito, e ao mesmo tempo criação do sujeito. Parece, assim, que Popper assume problemas maiores que previa ao defender o realismo.

\section{Defesa indireta e direta do realismo}

Segundo (GHINS, 2009) é uma prática comum em filosofia opor um realismo ao idealismo, bem como diferenciar ontologia de epistemologia. Segundo essa categorização, pode-se apresentar as seguintes questões que sintetizariam essas oposições:

a) Quais tipos de entidades existem? (Ontologia)

b) Como é o meio pelo qual temos o conhecimento? (Epistemologia)

Parece evidente que tais questões estão separadas por um critério apenas didático, pois uma parece estar relacionada à outra. De fato, conhecer é conhecer algo que existe, e, uma vez que aceitamos que existem tais e tais entidades, assumimos, com isso também a possibilidade cognitiva destas últimas. Nesse sentido, adotar uma postura epistemológica implica a aceitação de uma base ontológica e vice-e-versa. Assim, podemos conceber a antítese realismo-idealismo do seguinte modo: c) Existem entidades independentes do sujeito e de suas ideias. (realismo); d) Somente existem ideias ou também algo dependente delas. (idealismo).

A defesa popperiana do realismo pode ser dividida em duas etapas: a) defesa indireta, através do ataque à tese contrária (idealismo); b) defesa direta, pela suposição de uma estreita ligação entre o realismo e o objetivo da ciência. Popper critica o idealismo mas confessa que é uma tese metafísica tanto quanto o realismo:

A doutrina de que o Mundo é o meu sonho - isto é, a doutrina do idealismo - é irrefutável. Pode lidar com qualquer refutação interpretando-a como um sonho (tal como a psicanálise pode lidar com qualquer crítica psicanalizando-a). Mas a crença muito difundida de que a irrefutabilidade de uma teoria é um ponto a seu favor está errada. A irrefutabilidade não é uma virtude, mas sim um vício. Isso é igualmente válido para o realismo, infelizmente: é que o realismo também é irrefutável (POPPER, 1987, p. 108).

O realismo não é posto em causa na concepção de senso comum e Popper chega a afirmar que discutir tal concepção é uma "trivialidade" termo "real" é usado indiscriminadamente e se refere àquilo de que o fato ocorre, e não é apenas imaginativo ou abstrato, ou ainda, relativo apenas à experiência subjetiva. Assim, o idealismo parece supor que o uso do termo "real" se restrinja àquilo que pode ser concebido como uma ideia, e, mais que isso, a concepção mais

\footnotetext{
"Idem.
} 
radical a que chega é a concepção de que, já que somente as ideias são seguras, o mundo deve ser concebido como sendo o meu próprio sonho. Para Popper essa consequência é inaceitável, sobretudo pela consideração de todo o sofrimento real, causado pelas duas guerras mundiais. O sofrimento humano, portanto, está ligado a uma postura ética, a qual o filósofo não pretende abrir mão, e, assim sendo, decide combater o idealismo:

O meu argumento é o seguinte. Eu sei que não criei a música de Bach, nem a de Mozart; que não criei os quadros de Rembrant, nem os de Boticelli. Tenho toda a certeza de que nunca conseguiria fazer nada disso: são coisas que não estão em mim (POPPER, 1987, p. 109).

O argumento Popperiano parece, assim, se basear na ideia de complexidade como impossibilidade de criação de uma única mente. Mas, além disso, o argumento parece apresentar caráter primariamente subjetivo e não objetivo, como se esperaria de um argumento racional. O que parece mover o filósofo é por ter percebido no realismo uma importância considerável, visto que ele parece suportar uma concepção ética e não somente isso, mas também parece funcionar como uma concepção fundamental para a efetividade da ciência empírica. Isso fica claro quando se percebe que a característica da observação que ciência preserva está intimamente relacionada à existência de um mundo fixo e através do qual é possível constatar ou não a veracidade das teorias. Entretanto, a defesa indireta do realismo não é convincente, e, admitidamente parcialmente não racional:

Em várias ocasiões argumentei a favor do realismo. Os meus argumentos são em parte racionais e em parte ad hominem, e, até mesmo, em parte éticos. Parece-me que o ataque ao realismo, ainda que intelectualmente interessante e importante, não é de modo algum aceitável, sobretudo depois de duas guerras mundiais e do sofrimento real - e evitável - que estas injustificadamente provocaram (POPPER, 1987, p. 106).

Então, o motivo mais forte para essa defesa parece ser o contorno a consequências práticas da adoção de uma determinada postura, a qual, no caso do solipsismo seria a postura de negar a existência do sofrimento humano, já que no fundo seria apenas uma ilusão das minhas ideias. Parece que a forma como Popper defende indiretamente o realismo não se pretende convincente, senão a um nível de satisfação individual do próprio formulador do argumento. Pareceu, portanto, haver necessidade de um argumento mais sólido: o realismo como estando relacionado com o objetivo da ciência. Nesse sentido, Newton-Smith contribui:

(...) proponho-me a distinguir entre o objetivo manifesto da ciência e seu objetivo latente. Por objetivo manifesto entendo o fenômeno do qual parti - capacidade preditiva e manipulativa no nível observacional (o que Bacon tinha em mente com "poder sobre a 
natureza"). Há um consenso em que a ciência alcança isso. Para alguns filósofos, os instrumentalistas, tudo se resume a isso. Para outros, especialmente os realistas, o progresso em direção ao objetivo manifesto é um sinal, ainda que não infalível, do progresso em direção ao objetivo latente da ciência, que poderia ser a Verdade, ou, com Popper, a meta mais modesta de se aumentar a verossimilhança" (W.H. NEWTON-SMITH, 1997, p.24).

O maior problema que essa associação entre realismo e objetivo da ciência parece ter trazido é que assume a verdade correspondencial entre enunciados e estados de coisa. Nesse sentido, Caponi (1996) mostra a debilidade dupla de Popper ao vincular o falseasionismo ao realismo metafísico por: a) identificar "investigação científica" com a "busca da verdade" ausente em L.Sc.D. b) pretender justificar a presunção metafísica das leis da natureza baseado na motivação psicológica de que a discussão racional deva ser balizada na busca da verdade objetiva. ${ }^{12}$

Mas essa concepção de verdade nos parece, conforme Caponi (1996) também assinalou, poderia ser contornada, ao pensarmos esta como uma idealização da aceitação racional. ${ }^{13}$ Assim, se nota que a razão pela qual Popper assume o realismo, e o que o motiva a defendê-lo é dupla: a) porque há uma concepção ética desfavorável na sua rejeição; b) o realismo parece funcionar como um pressuposto, tanto para ciência, quanto para a concepção de senso comum, pois com frequência se faz asserções sobre a realidade dos corpos físicos e isso implica que há uma realidade externa e independente.

Assim, foi possível observar até aqui que o realismo passou a ser defendido firmemente pelo Popper da maturidade e os alicerces dessa defesa, pode-se entender como sendo uma base ética e uma crença em regularidades na natureza, que pode ser expressa sob leis e, também pelo caso de essas regularidades se referirem à própria estrutura do mundo, o realismo pode ser entendido como metafísico. Há, portanto, uma metafísica na filosofia popperiana, atrelada ao seu método e relacionada com sua epistemologia falibilista. Cabe agora examinarmos qual o fundamento de sua perspectiva metafísica, ou daquilo que se pode entender por sua própria visão de mundo, ou, cosmologia.

\section{Cosmologia propensitiva e as propostas experimentais de popper}

Popper assevera que os problemas em ciência podem resultar da relação entre a teoria e um Programa Metafísico de Investigação. Com isso pretende mostrar que o

\footnotetext{
${ }^{12}$ Cf. CAPONI, 1996, pp.20-21.

${ }^{13}$ Isto é, quando supomos que estamos mais próximos da verdade por conta de uma teoria ter sido corroborada, ou, pelo menos nos afastado dos erros, por termos falseado uma teoria, na verdade estamos aceitando racionalmente algumas proposições tendo em vista que tudo o que era possível avaliar foi executado. Portanto, esta parece ser uma alternativa internalista mais compatível com o falseasionismo e, ao mesmo tempo, como um contorno das dificuldades decorrentes dos compromissos.
} 
processo de criação de uma teoria está diretamente relacionado com uma perspectiva metafísica de mundo que, de certa forma exerce influência direta, isto é, parte dos seguintes pressupostos: a) os cientistas muitas vezes são guiados em suas pesquisas por um Programa Metafísico de Investigação; b) tais concepções metafísicas apresentam um caráter programático, isto é, determinam de antemão a pesquisa posterior; c) os programas têm um caráter inicialmente não testável, ou seja, possuem um elemento subjetivo não falsificável pela experiência em uma primeira instância. ${ }^{14}$ Ele assim assevera:

Ao empregar esse termo [programa metafísico de investigação], pretendo chamar a atenção para o fato de que em quase todas as fases do desenvolvimento das ciências estamos sob influência de ideias metafísicas, isto é, ideias não testáveis, ideias que não só determinam os problemas de explicação que vamos escolher, como também os tipos de resposta que vamos considerar corretos, satisfatórios ou aceitáveis e como melhoramentos ou progressos relativamente a respostas anteriores (POPPER, 1989, p. 169).

Ele pretende chamar a atenção para o fato de que as concepções metafísicas dos cientistas os orientam em sua pesquisa, e isso influencia no processo de escolha de respostas aos problemas. Popper não está isento de uma influência metafísica. Ele elabora e desenvolve a sua teoria das propensões em um momento posterior à escrita da Lógica da Pesquisa Científica, que pode ser caracterizada por uma concepção tríplice: objetivista - indeterminista - realista. Assim sendo, quando ele analisa a história da ciência também está assumindo para si uma perspectiva metafísica, mas comenta o que entende sobre esse termo:

Chamo metafísica a tais programas de investigação também porque eles resultam de perspectivas gerais sobre a estrutura do mundo e, ao mesmo tempo, de perspectivas gerais sobre a situação problemática da cosmologia física. Chamo-lhes programas de investigação porque, juntamente com uma ideia sobre quais são os problemas mais prementes, compreendem uma ideia geral sobre o aspecto que teria uma solução satisfatória para os problemas em causa (POPPER, 1989, p. 169).

Do mesmo modo que o seu programa metafísico, os outros programas procuram resumir a explicação da realidade em teses bastante sintéticas e ricas em conteúdos. Isso significa dizer que são proposições que contêm, em si mesmas, considerável poder explicativo para certos eventos do mundo. Todos os programas metafísicos, no seu entender, estão em disputa, na medida em que visam maior nível de abstração e abarcamento do mundo possível em termos argumentativos. Assim sendo, um programa metafísico tem a pretensão de abarcar a realidade através de poucas proposições, ricas em teor explicativo e de conteúdo. Com efeito, Popper

${ }^{14}$ POPPER, 1989, p. 169. 
(1989, p. 170-171) apresenta dez exemplos desses programas, desde os filósofos présocráticos até a física moderna. Os itens da sua lista são:

1) O Universo-bloco de Parmênides

2) O Atomismo de Demócrito e Leucipo

3) a Geometrização de Pitágoras e seguido por Platão

4) O Potencialismo de Aristóteles

5) A física renascentista de Copérnico, Bruno, Kepler e Descartes

6) A Teoria Mecanicista do Mundo de Hobbes, Descartes, Boyle

7) O Dinamismo de Newton

8) Os campos de força de Faraday e Maxwell

9) A Teoria Unificada de Campo de Riemann, Einstein, Schrödinger

10) A Interpretação Estatística da Teoria dos Quanta de Max Born.

Na perspectiva popperiana, os programas metafísicos partilham da característica de serem inicialmente não testáveis, isto é, não se pode comprová-los nem falsificá-los em primeira instância, e também operam segundo uma programação de pesquisa, na medida em que veem a nortear os trabalhos dos cientistas. O que Popper faz, mais adiante, e que é de grande relevância para a racionalidade metafísico-científica é que propõe "um novo programa de pesquisa, assentado na ideia da realidade das disposições e na interpretação da probabilidade em termos de propensões." (POPPER, 1974, p. 160).

Mas antes mesmo da elaboração dessa teoria cosmológica, na sessão 77 da Lógica da Pesquisa Científica, intitulada “experimentos decisórios”, Popper propôs um experimento procurando testar a alegada completude da teoria quântica. Tal experimento sofreu críticas do próprio Einstein, e levou Popper a considera-lo como um erro digno de arrependimento. Ainda assim, de acordo com Jammer (1974) não é impossível de se aceitar a possibilidade de que esse erro grosseiro popperiano tenha influenciado Einstein na elaboração do experimento imaginário EPR (EinsteinPodolsky-Rosen) o qual pareceu supor que, ao se aceitar os pressupostos da mecânica quântica teríamos de aceitar a ação à distância.

Já no terceiro volume do pós-escrito à Lógica da Pesquisa Científica, intitulado A Teoria dos Quanta e o Cisma na Física Karl Popper faz uma segunda proposta experimental no qual pretendeu averiguar se é nosso conhecimento acerca de um caso que causa incerteza ou se a realidade física produz dispersão estatística. Durante bom tempo a proposta popperiana foi discutida, mas, somente em 1999 Kim e Shih procuraram realizar tal experimento. As conclusões que Qureshi comenta terem surgido a partir de tal proposta e das suas próprias interpretações são as seguintes: 
Atualmente estamos em condições de parar e refletir sobre o porquê de o experimento popperiano ter gerado tanta controvérsia. $\mathrm{O}$ problema foi que Popper e a maioria de seus críticos chegaram a uma conclusão errada sobre quais resultados o experimento produziria. Isso ocorreu porque ninguém se importou em realizar uma análise rigorosa, mas usaram algumas noções comumente entendidas sobre medição que os levaram a uma conclusão errada. Com muito trabalho teórico e experimental em sistemas quânticos em nossa bagagem, agora estamos mais sábios e nos damos conta que a mecânica quântica é cheia de tais armadilhas. O experimento do Popper se provou útil em entender o que são correlações quânticas, e mais importante, o que elas não são (QURESHI, 2012, p.30).

Nota-se, portanto, que Popper contribuiu para a discussão em torno da física do século XX, ainda que de modo sutil. Mesmo que os resultados de seu experimento não tenham conduzido os resultados esperados, como comenta Qureshi (2012). Popper procurou sempre combater qualquer forma de dogmatismo e anti-racionalismo e isso ficou evidente na crítica ao idealismo e à ideia de completude da teoria quântica. Isso por si bastaria para considerarmos o valor de sua filosofia, e, ainda que os resultados de seus experimentos não tenham sido como ele desejava, a crítica racional produzida por ele é certamente um ganho para a ciência. Além disso, a sua visão de mundo oferecida pela teoria das propensões, enquanto conjectura de um universo aberto, isto é, pleno de possibilidades ou propensões para algo parece permitir uma compreensão abrangente da realidade. Com efeito, a sua teoria metafísica ou cosmológica das propensões abre possibilidades para uma compreensão indeterminista e crítica, aplicável não só à física, no sentido de estabelecimento um conjunto de probabilidades, mas também à biologia, à economia e à psicologia.

\section{Considerações finais}

Popper parece ter escrito a Lógica da Pesquisa sob um pano de fundo realista, mas, somente no pós-escrito encontrou uma forma de defender essa concepção metafísica de forma crítica. O realismo mostrou-se como tendo duas formulações: senso comum e metafísico. A primeira formulação parece mais facilmente conciliável com boa parte das teorias científicas, e de certa forma, indubitável, sobretudo para quem admite a plausibilidade de uma ética. Já a segunda formulação, por um lado parece ter trazido aparentes inconsistências à sua filosofia. Por outro lado, parece ter levado a uma melhor organização de sua epistemologia e metodologia. Além disso, a sua concepção de ciência como cosmologia possibilitou um apanhado mais geral sobre a estrutura da realidade, e isso parece estar diretamente relacionado com as suas propostas de correspondência com a realidade referida. 
Ainda que no presente trabalho não haja espaço para as minúcias de um exame dos resultados comentados por Qureshi (2012) sobre a segunda proposta de experimento (em Q.T.S.P), é importante notar que Popper não só procurou compreender as implicações das teorias que estavam em desenvolvimento em seu tempo como também formulou uma teoria cosmológica com teor universal e, a partir dela sugeriu uma nova visão de mundo. Portanto, parte do interesse de Popper em sugerir experimentos em física parece residir na busca por testes para a sua própria perspectiva e isso não exclui a possibilidade do surgimento de novos problemas, até para sua filosofia. Mesmo assim o filósofo não desiste de se posicionar com relação a uma ética, uma ontologia e uma epistemologia, sugerindo testes em física. Isso pode se considerar uma postura não de pequeno pensador, mas de um filósofo de grande valia para a história da filosofia contemporânea.

\section{Referências}

CAPONI, G. Pautas para uma crítica da ciência realmente existente: o legado epistemológico de Karl Popper. Campinas, 1992. 417f. Tese (Doutorado em Lógica e Filosofia da Ciência) UNICAMP, 1992.

. Necesidad y posibilidad de uma fundamentación internalista para el falsacionismo. Revista venezolana de Filosofía, Caracas, n. 34, pp.7-32, 1996.

FERNANDES, S. L. De C. Foundations of Objective Knowledge. Revisão de Tese (doutorado). Boston studies in the philosophy, University of London, v. 86, 1981.

GHINS, M. “Realism”, 2009. Disponível em:<http://www.inters.org/realism>. Acesso em: 9 de jun.2017.

JAMMER, M. The Philosophy of Quantum Mechanics - The Interpretations of Quantum Mechanics in Historical Perspective. New York: John Wiley \& Sons, 1974.

KIM Y-H, S. Y. Experimental realization of Popper's experiment: violation of the uncertainty principle? Foundations of Physics 1999; 29 (12): pp.1849-1861.

NEWTON-SMITH, W. H. Popper, ciência e racionalidade. In: O’HEAR, A. (Org.); Karl Popper: Filosofia e Problemas. Tradução de Luiz Paulo Rouanet. São Paulo: Fundação Editora da UNESP/Cambridge, 1997. p. 147-176.

POPPER, K. R. A Teoria dos Quanta e o Cisma na Física. - Pós escrito à Lógica da Pesquisa Científica, Volume III. Lisboa: Publicações Dom Quixote, 1989 [1982].

. A Lógica da Pesquisa Científica. 2. ed. São Paulo: Cultrix, 2013 [1959].

. Conhecimento Objetivo: Uma abordagem Evolucionária. Tradução de Milton Amado.

Belo Horizonte: Itatiaia/SP: Edusp, 1999 [1972].

. O Realismo e o Objectivo da Ciência. - Pós escrito à Lógica da Pesquisa Científica, Volume I. Lisboa: Publicações Dom Quixote, 1987 [1982].

Unended Quest. An Intellectual Autobiography, London: Routledge, 2005.

. Autobiografia Intelectual. Tradução Leônidas Hegenberg e Octanny Silveira da Mota. São Paulo: Cultrix / Ed. USP, 1974.

QURESHI, T. Popper's Experiment: A Modern Perspective. New Delhi/India: Centre for Theoretical Physics, 2012. 
A cosmologia realista de Popper e sua contribuição para a discussão racional em Física

Submissão: 08.07.2017 / Aceite: 11. 10. 2017 